\title{
Environmental public health risks in European metropolitan areas within the EURO-HEALTHY project
}

Christina Mitsakou ${ }^{\text {a,* }}$, Sani Dimitroulopoulou ${ }^{a}$, Clare Heaviside ${ }^{\text {a,b }}$, Klea Katsouyanni ${ }^{\text {, }}$, Evangelia Samoli ${ }^{\text {, }}$ Sophia Rodopoulou c ${ }^{\text {, }}$ Claudia Costa ${ }^{\text {}}$, Ricardo Almendra ${ }^{\mathrm{d}}$, Paula Santana ${ }^{\mathrm{d}}$, Marc Marí Dell'Olmo e,f, Carme Borrell $^{\text {e,f }}$, Diana Corman ${ }^{\mathrm{g}}$, Nicolás Zengarini ${ }^{\mathrm{h}}$, Patrick Deboosere ${ }^{\mathrm{i}}$, Conrad Franke ${ }^{\mathrm{j}}$, Jürgen Schweikart $^{\mathrm{j}}$, Michala Lustigova ${ }^{\mathrm{k}}$, Christos Spyrou ${ }^{1}$, Kees de Hoogh ${ }^{\mathrm{m}, \mathrm{n}}$, Daniela Fecht ${ }^{\mathrm{o}}$, John Gulliver ${ }^{\mathrm{o}}$, Sotiris Vardoulakis ${ }^{\mathrm{a}, \mathrm{p}}$

a Centre for Radiation, Chemical and Environmental Hazards (CRCE), Public Health England, UK

${ }^{\mathrm{b}}$ Environmental Change Institute, University of Oxford, UK

c Department of Hygiene, Epidemiology and Medical Statistics, Medical School, National and Kapodistrian University of Athens, Greece

d Centre of Studies in Geography and Spatial Planning, Department of Geography and Tourism, University of Coimbra, Portugal

e Agencia de Salut Publica de Barcelona, Spain

${ }^{f}$ CIBER Epidemiología y Salud Pública (CIBERESP), Madrid, Spain

g Karolinska Institutet, Sweden

h Consorzio per il Sistema Informativo, CSI, Piemonte, Italy

${ }^{i}$ Department of Sociology, Vrije Universiteit, Brussels, Belgium

j Beuth University of Applied Sciences, Berlin, Germany

${ }^{\mathrm{k}}$ Faculty of Science, Charles University, Czechia

${ }^{1}$ Department of Atmospheric Physics, School of Physics, National and Kapodistrian University of Athens, Greece

${ }^{\mathrm{m}}$ Swiss Tropical and Public Health Institute, Basel, Switzerland

${ }^{\mathrm{n}}$ University of Basel, Basel, Switzerland

${ }^{\circ}$ UK Small Area Health Statistics Unit, MRC-PHE Centre for Environment and Health, Imperial College London, UK

${ }^{\mathrm{P}}$ Institute of Occupational Medicine, UK

\section{H I G H L I G H T S}

- Air pollution was linked to many attributable deaths, exceeding $2 \mathrm{k}$ per year in cases.

- The road traffic fatalities have decreased compared to earlier years.

- Road traffic noise was associated with deaths comparable to the traffic fatalities.

- In South-European areas, up to 800 deaths were associated with high temperatures.

- The development of green spaces could be very beneficial in some areas.
G R A P H I C A L A B S T R A C T

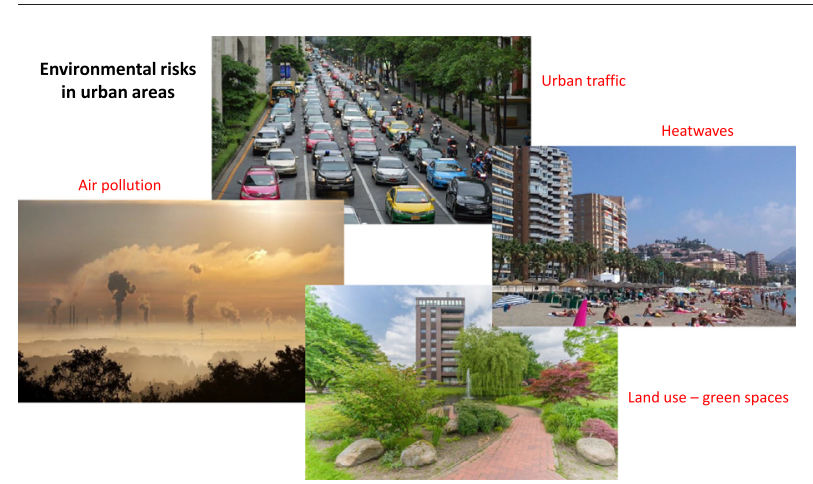

\section{A R T I C L E I N F O}

\section{Article history:}

Received 3 September 2018

Received in revised form 3 December 2018

Accepted 9 December 2018

Available online 12 December 2018

\begin{abstract}
A B S T R A C T
Urban areas in Europe are facing a range of environmental public health challenges, such as air pollution, traffic noise and road injuries. The identification and quantification of the public health risks associated with exposure to environmental conditions is important for prioritising policies and interventions that aim to diminish the risks and improve the health of the population. With this purpose in mind, the EURO-HEALTHY project used a consis-
\end{abstract} tent approach to assess the impact of key environmental risk factors and urban environmental determinants on

\footnotetext{
* Corresponding author.

E-mail address: christina.mitsakou@phe.gov.uk (C. Mitsakou).
} 
Editor: Pavlos Kassomenos

\section{Keywords:}

Environmental public health risks

Health impact assessment

Air pollution

Green spaces

Road traffic noise

Attributable mortality public health in European metropolitan areas. A number of environmental public health indicators, which are closely tied to the physical and built environment, were identified through stakeholder consultation; data were collected from six European metropolitan areas (Athens, Barcelona, Lisbon, London, Stockholm and Turin) covering the period 2000-2014, and a health impact assessment framework enabled the quantification of health effects (attributable deaths) associated with these indicators. The key environmental public health indicators were related to air pollution and certain urban environmental conditions (urban green spaces, road safety). The air pollution was generally the highest environmental public health risk; the associated number of deaths in Athens, Barcelona and London ranged between 800 and 2300 attributable deaths per year. The number of victims of road traffic accidents and the associated deaths were lowest in the most recent year compared with previous years. We also examined the positive impacts on health associated with urban green spaces by calculating reduced mortality impacts for populations residing in areas with greater green space coverage; results in Athens showed reductions of all-cause mortality of 26 per 100,000 inhabitants for populations with benefits of local greenspace. Based on our analysis, we discuss recommendations of potential interventions that could be implemented to reduce the environmental public health risks in the European metropolitan areas covered by this study.

(C) 2018 Elsevier B.V. All rights reserved.

\section{Introduction}

Cities are expected to play a key role in delivering the Europe 2020 strategy for smart, green and inclusive growth (EU, 2014). Compared to other parts of the world, Europe is highly urbanised. According to the harmonised definition by Eurostat and the Organisation for Economic Co-operation and Development (OECD), urban areas - defined as cities, towns and suburbs - provide a home to $72 \%$ of the EU-28's population; $41 \%$ in cities and $31 \%$ in towns and suburbs (Eurostat, 2016). Densely populated urban areas in Europe are facing environmental health challenges associated with multiple risk factors including air pollution, climate change, environmental noise and road accidents (Vardoulakis et al., 2016).

Despite improvements in air quality in many European countries over recent decades, air pollution still has a significant impact on public health. Long-term exposure to fine particulate matter $\left(\mathrm{PM}_{2.5}\right)$ and nitrogen dioxide $\left(\mathrm{NO}_{2}\right)$ has been associated with cardiovascular and respiratory mortality (COMEAP, 2010, 2016; Hoek et al., 2013). In UK, the mortality burden of long-term exposure to the air pollution mixture $\left(\mathrm{NO}_{2}\right.$ and $\left.\mathrm{PM}_{2.5}\right)$ in 2013 was estimated as an effect equivalent to 28,000 to 36,000 deaths at typical ages (COMEAP, 2018). Short-term exposure to ozone $\left(\mathrm{O}_{3}\right)$, has been associated with increasing hospital admissions and risk of mortality (COMEAP, 2015; Atkinson et al., 2016; Samoli et al., 2016). Motorised traffic provides a major source of air pollution in European cities, particularly for $\mathrm{NO}_{2}$ (Gulia et al., 2015). Due to the proximity of urban populations to road traffic, characterising and tackling traffic related air pollution is a public health priority (Vardoulakis et al., 2018).

Exposure to noise is another important environmental health risk, as it disturbs communication, concentration, relaxation and sleep and thus provokes adverse emotional reactions in some people (Miedema and Vos, 2007). The World Health Organisation (WHO) commissioned a number of systematic review and meta-analyses on effects of environmental noise on various health outcomes, and recently published its Environmental Noise Guidelines for Western Europe (WHO, 2018a). Road traffic noise in particular has been linked to cardiovascular disease, sleep disturbance and annoyance (Kluizenaar et al., 2001; Defra, 2014; Munzel et al., 2014; Halonen et al., 2015; Guski et al., 2017; Basner and McGuire, 2018; van Kempen et al., 2018).

A further environmental public health risk related to traffic is road traffic injuries, as it is ranked as one of the leading causes of deaths and disabilities worldwide (Wang et al., 2016). In the European Region road traffic injuries are responsible for thousands of fatalities (WHO, 2013a; Shen et al., 2013).

Climate change is likely to aggravate certain health risks in European cities by increasing the frequency and severity of extreme weather events, such as heatwaves and floods. Projected increases in temperature and the frequency of heatwaves in future is likely to increase the risk of heat related mortality and morbidity (Analitis et al., 2008; Gasparrini et al., 2015; Basu et al., 2008; Gronlund et al., 2014). The effects of heat are often exacerbated in cities, due to the urban heat island effect (Heaviside et al., 2017). Europe experienced a severe heatwave in 2003 and in France the number of heat-related deaths reached 15,000 in the first week of August 2003 (Robine et al., 2008).

Increasing and improving green spaces and cycling infrastructure are often seen as key interventions for creating healthier and more sustainable urban environments. Recent studies have identified benefits from access to urban green spaces, through various pathways, such as improved air quality, heat reduction and enhanced physical activity that may have a synergistic effect (WHO, 2016, 2017; Pinto et al., 2017). Contact with natural environments, such as green spaces, has been linked to improved perceived and objective health outcomes and wellbeing (James et al., 2015) and Dadvand et al. (2016) assessed the association between green spaces and subjective general health and mental health status. A link between green spaces and decreased mortality and morbidity related to cardiovascular disease (CVD) has also been reported (e.g. Tamosiunas et al., 2014).

As part of the EURO-HEALTHY project (http://www.euro-healthy. $\mathrm{eu} /$ ), a multidimensional set of indicators, reflecting health determinants and health outcomes in Europe, were selected based on reviews of scientific evidence, and the views of health experts and stakeholders through a Delphi selection process (Freitas et al., 2018).

The quantification of health impacts or benefits associated with environmental factors in urban environments has been carried out in some cities through application of a Health Impact Assessment (HIA), for the purpose of assessing the effects of policies and interventions. A HIA provides a methodological framework for the characterisation of health impacts (either benefits or risks) of policies, projects or interventions, which may have an influence on public health, either directly or indirectly (WHO, 2018b; Woodcock et al., 2014; Perez et al., 2015; Mueller et al., 2016). Dimitroulopoulou and Mitsakou (2018) carried out a comprehensive review to investigate the HIA methods that have or can be used to evaluate health outcomes from local travel plans and transport interventions; HIA methods ranged from those that assess only the air pollution associated health risks to those that also consider multiple health pathways, such as noise, access to green spaces.

Given the complexity and multiple factors relating to health of urban populations, the aim of this study is to assess the impact of key environmental risk factors (i.e. air pollution, road traffic noise, extreme high temperature) and urban environmental determinants (urban green spaces, road safety) on public health across European metropolitan areas by applying a HIA framework and identifying temporal changes. Comparisons of environmental public health risks across space and time are intended to support the prioritisation of interventions in order to diminish risks and improve health in different European cities. 


\section{Methods}

Among the challenges for achieving the aims of the study was the selection and collection of comparable data across the European metropolitan areas, as well as the selection and formulation of exposureresponse functions (ERFs) that could be applied to different geographical areas when carrying out the HIA. Details are provided in the following paragraphs.

\subsection{Data and indicators}

A wide range of physical and built environment indicators were identified through a literature review process (Vardoulakis et al., 2016). In addition to the set of indicators selected through the Delphi process (Freitas et al., 2018), an iterative stakeholder consultation process focussing on the environmental indicators was carried out, where additional indicators were selected for consideration (Table A1 of the Appendix A). Environmental indicators which are not directly or quantifiably associated with health outcomes, such as the recycling rate of municipal waste, were not considered in the current analysis. The indicators that were eventually retained and analysed in this study were selected based on their spatial and temporal data availability, quality and compatibility across the studied European areas and periods; these are the annual mean $\mathrm{NO}_{2}$ concentrations, exposure to road traffic noise, daily mean/maximum temperature, urban green spaces (the percentage of surface area classed as green) and two indicators related to road safety (victims in road accidents, fatality ratio due to road traffic accidents).

The metropolitan areas included in the analysis (based on data availability for the selected indicators) are: Athens, Barcelona, Lisbon, London, Stockholm and Turin (map and population density in Fig. 1; population trees, along with the total population, in Fig. A1 of the Appendix A). The available data in the period 2000-2014 were collected for the metropolitan areas. The geographical unit for all collected data is the municipality and in particular the Local Administrative Units level 1 (LAU1) for Athens, Lisbon and London or level 2 (LAU2) for Barcelona, Stockholm and Turin, as defined by EUROSTAT. The data availability for environmental indicators and health outcomes per metropolitan area is summarised in the Appendix A (Table A2).

It should be noted that in Turin, the majority of the population resides in the central municipality, while in other metropolitan areas, the population is more evenly distributed across municipalities (e.g. Athens, London).

The data were compiled, validated and processed consistently within the project (Santana et al., 2017; Costa et al., 2017), in order to be used in the HIAs.

\subsection{Annual mean $\mathrm{NO}_{2}$ concentrations}

$\mathrm{NO}_{2}$ was used here as a surrogate of air pollution in the urban areas, where traffic is one of the dominant sources. Annual mean concentrations of $\mathrm{NO}_{2}$ (years: 2005, 2006, 2007, 2010) were derived for Europe at $100 \mathrm{~m} \times 100 \mathrm{~m}$ spatial resolution, from Land Use Regression (LUR) models (Vienneau et al., 2013; de Hoogh et al., 2016). $\mathrm{NO}_{2}$ concentration data were collected and analysed rather than $\mathrm{PM}_{2.5}$ concentrations due to the greater data availability in time $\left(\mathrm{PM}_{2.5}\right.$ data were only available for 2010). The gridded data were spatially analysed to produce the municipal averages of annual mean $\mathrm{NO}_{2}$ concentrations (by averaging the $100 \mathrm{~m} \times 100 \mathrm{~m}$ centroids across a municipality) for each year.

The 5th, 50th (median value) and 95th percentiles, as well as the population-weighted values (based on the municipal level values) of the annual mean $\mathrm{NO}_{2}$ concentrations across the municipalities of each
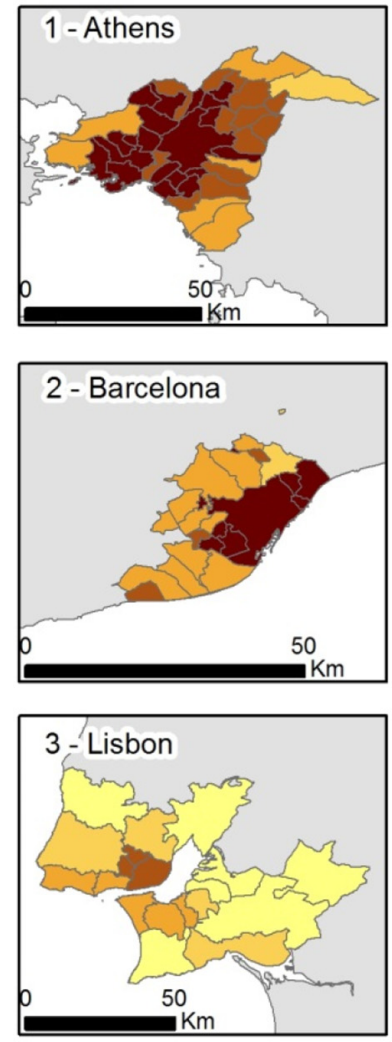
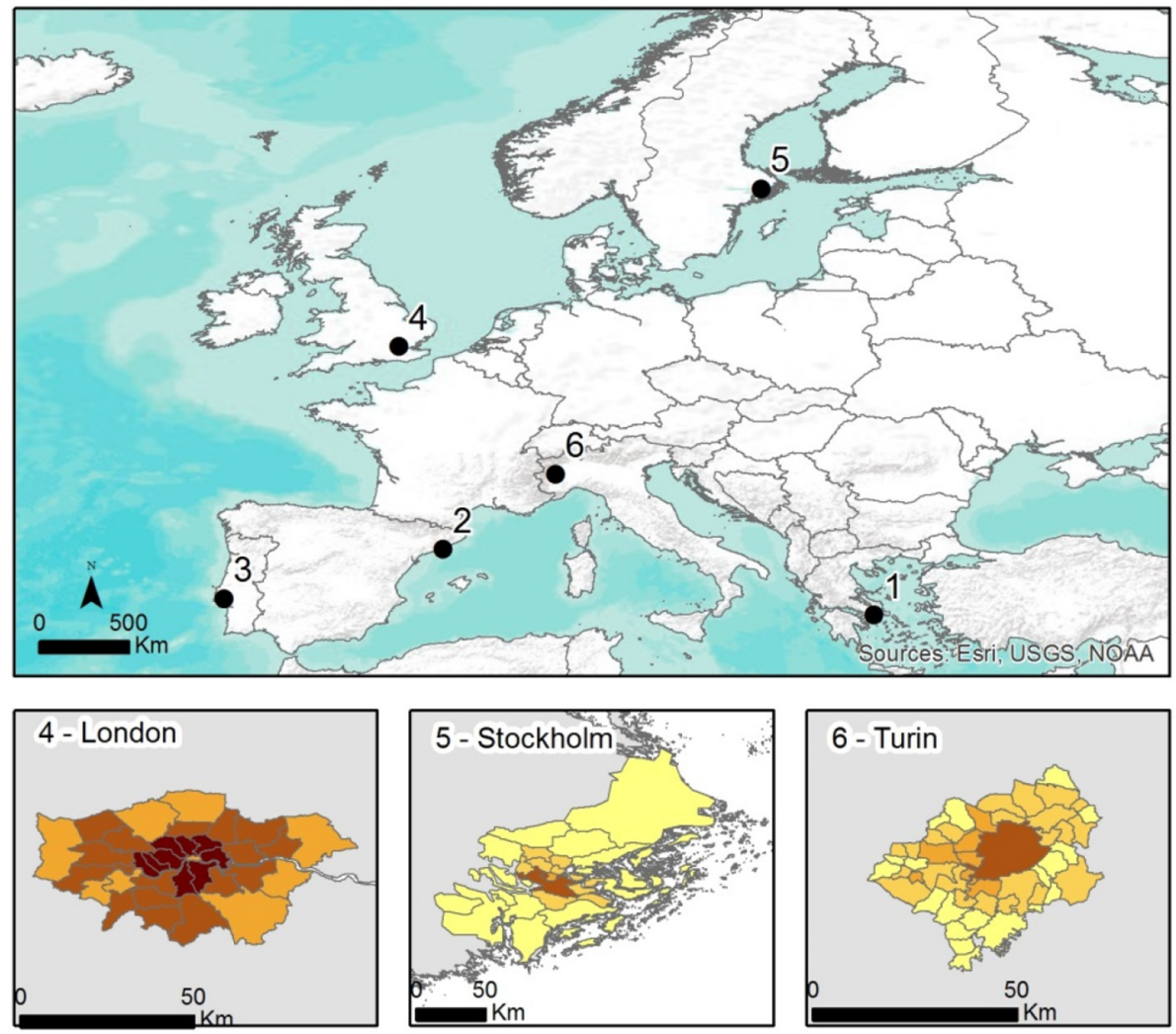

Population density (inhab./km2) in 2011:

Fig. 1. European metropolitan areas and population density in 2011. 
metropolitan area are summarised in the Appendix A (Table A3). The $\mathrm{NO}_{2}$ concentrations were higher in Athens, London and Barcelona (median values ranging between 27 and $50 \mu \mathrm{g} / \mathrm{m}^{3}$ in areas and years), while in Athens and London they decreased in 2010 compared to the previous years. The population-weighted values are close to the median concentration values (50th percentiles) in Athens and London, which denotes a relatively uniform distribution of the population across the municipalities of the metropolitan areas. In Barcelona, Lisbon and Stockholm, the population-weighted values are greater than the median concentration values and in Turin the population-weighted values are similar to the 95th percentiles of the concentrations; which indicates that the majority of the populations reside in the most polluted parts of the metropolitan areas.

\subsection{Exposure to road traffic noise}

The indicator 'population exposed to traffic noise' describes the percentage of the population that is exposed to road traffic noise, $\mathrm{L}_{\mathrm{den}}$ : $55-59 \mathrm{~dB}$ or $\mathrm{L}_{\mathrm{den}}>55 \mathrm{~dB}$ when data at different noise bands was not available, where $L_{d e n}$ represents the day-evening-night equivalent sound level over a 24-hour period $\left(\mathrm{L}_{\mathrm{den}}>55 \mathrm{~dB}\right.$ corresponds to the requirement for exposure mapping under the Environmental Noise Directive). In the recently published environmental noise guidelines (WHO, 2018a), the $L_{d e n}$ : $53 \mathrm{~dB}$ represents the road traffic noise exposure levels above which experts are confident that there is an increased risk of adverse health effects.

The data were collected from the official institutes of the countries or from research studies. Information on the noise data and sources is in the Appendix A (Table A4). In all the metropolitan areas, $90 \%$ or more of the population is exposed to road traffic noise $\mathrm{L}_{\mathrm{den}}>55 \mathrm{~dB}$. In the areas where data were available for more than a year, no temporal trend was identified.

\subsection{Urban green spaces}

This indicator represents the percentage of the municipality's surface area (\%) covered by green spaces. The data (resolution: 0.5-1 $\times 10^{-2} \mathrm{~km}^{2}$ ) were downloaded from the Urban Atlas of the European Environment Agency (Copernicus, 2018) for 2 years - 2006 and 2012 - (vector data code: 14100 green urban areas, 14200 sports and leisure facilities, 30000/31000 forests and semi-natural areas) and were spatially analysed to obtain values at municipal level. The Urban Atlas provides high spatial resolution and consistency datasets in the European region and the flexibility for the user to select and consider in the analysis a variety of land-use categories (e.g. sports facilities, agricultural areas). The Urban Atlas has been used to create an urban green space indicator for public health (van den Bosch et al., 2016).

The quartiles of the percentages of urban green spaces across the municipalities of the metropolitan areas are presented in the Appendix A (Fig. A2). In Stockholm, the median values of the urban green areas in 2006 and 2012 was higher than 50\%, while in the other areas the median values are lower than $20 \%$. In Lisbon and Turin, there is a significant variability in green spaces among the municipalities of the metropolitan areas, which is reflected in the large difference between the quartiles.

\subsection{Daily mean/maximum temperature}

We analysed daily mean/maximum temperature and dew point data for 3 years (2001, 2006 and 2011). The data were obtained from meteorological stations in each metropolitan area (Athens: 167160 Hellinikon, Barcelona: 81810 Aeropuerto, Lisbon: 85790 Cago Coutinho, London: 37720 Heathrow airport, Stockholm: 24840 Observato and Turin: 160590 Caselle) and downloaded via the National Oceanic and Atmospheric Administration (NOAA), U.S. Department of Commerce website (https://www7.ncdc.noaa.gov/). The number distribution (number of days) of the daily mean temperature values for the metropolitan areas is illustrated in the Appendix A (Fig. A3).

In Athens, the daily mean temperature exceeded $30{ }^{\circ} \mathrm{C}$ on 19,12 and 53 days in 2001, 2006 and 2011 respectively. In Lisbon, the daily mean temperature exceeded $30{ }^{\circ} \mathrm{C}$ only in 2006; in Barcelona, Lisbon and Turin there were few days per year with temperatures within 26-30 ${ }^{\circ} \mathrm{C}$ (varying within 4-21 days across the years and the areas). The highest temperatures in London and Stockholm were below $26^{\circ} \mathrm{C}$, while the daily mean temperature in Stockholm was below $-2{ }^{\circ} \mathrm{C}$ many days in a year (ranging between 15 and 50 days).

\subsection{Road safety}

The indicators collected and developed are a) 'victims in road accidents' - number of injured and killed persons in road traffic accidents per 100,000 inhabitants and b) 'fatality ratio due to road traffic accidents' - ratio of the number of deaths to injured cases in road traffic accidents.

The victims in road accidents showed large variability across and within the metropolitan areas and there are noticeable differences between the two years analysed (see Appendix A, Fig. A4). In general, the number of victims were lower in Athens and even lower in Stockholm (not available data at municipal level) and higher in municipalities of Lisbon and Turin and the central municipalities of Barcelona.

The average fatality ratio due to road accidents across municipalities is summarised in the Appendix A (Table A5). The fatality ratios were higher in Athens and Turin; the average values were lower in 2011 compared to 2001 in all the municipality areas apart from Athens where the fatality ratios remained at the same levels.

\subsection{Health outcomes - mortality}

Baseline health data were collected for the municipalities of each metropolitan area from the official statistical offices. The annual mortality data for a number of causes were collected in order to be associated with the long-term exposure to the identified environmental risks. The deaths due to cardiovascular diseases (ICD10: I00-I99) and all natural causes (excluding external causes, land transport accidents - ICD10: V01-V99 and suicide - ICD: X60-X84), based on deaths in 5-year age groups, were used. Daily data of all-cause deaths were collected for Athens, Lisbon and London, in order to carry out the heat-related mortality analysis.

Mortality attributable to air pollution was calculated for adults aged 30 years and above $(30+)$, consistent with the design of the original epidemiological cohort studies, which provided the exposure-response functions; therefore the data corresponding to age groups $30+$ (e.g. $30-34,35-39$, etc.) were aggregated respectively. For Turin, the first age group covers ages 0 to 49 and therefore the calculations were based on aggregating the health data for all age groups, under the assumption that mortality excluding external causes at ages $0-30$ years is very low; hence the inclusion of this age group did not have a significant effect on the analysis.

\subsection{Attributable deaths}

For the environmental public health indicators, the attributable number of deaths was estimated by scaling the relative risk $(R R)$ obtained by the exposure-response functions (ERFs) at the specific exposure level. A literature review of ERFs that associate those indicators with health outcomes was carried out and meta-analysis was conducted when sufficient previous information was available (i.e. for effects following long-term exposure to $\mathrm{NO}_{2}$ ) in order to obtain one pooled estimate of the $R R$ (see Appendix B). For the associations between an environmental exposure and mortality where insufficient evidence was available, the meta-analysis did not provide a $R R$ to be applied; in these cases the $R R$ from a robust epidemiological study (i.e. for effects 
of long-term exposure to road traffic noise exposure and for effects of short-term exposure to high temperature) or review study (i.e. for effects of green spaces) was used. The selected ERFs are summarised as follows:

For $\mathrm{NO}_{2}$ exposure: the $\mathrm{RR}$ of all-cause mortality associated with longterm exposure to $\mathrm{NO}_{2}$, as calculated through the meta-analysis, is 1.020 (95\% CI: $1.018,1.022$ ) per $10 \mu \mathrm{g} / \mathrm{m}^{3}$ (see Appendix B). The scaled relative risk $R R^{\prime}$ corresponding to an increment or difference in exposure above $10 \mu \mathrm{g} / \mathrm{m}^{3}$ used in the ERF is calculated as shown in the Eq. (1), following Gowers et al. (2014):

$$
\boldsymbol{R} \boldsymbol{R}^{\prime}=\boldsymbol{R} \boldsymbol{R}^{\boldsymbol{x} / \mathbf{1 0}}
$$

A scenario of $\mathrm{NO}_{2}$ reduction is investigated, in order to provide estimates of the potential health benefits from reducing air pollution levels to a common cut-off value. For this, the relative risk is adjusted as:

$\boldsymbol{R} \boldsymbol{R}^{\prime}=\boldsymbol{R} \boldsymbol{R}^{\left(\boldsymbol{x}-\boldsymbol{x}_{0}\right) / 10}$

where $x_{0}$ is a threshold air pollutant concentration value. Here, the value of $20 \mu \mathrm{g} / \mathrm{m}^{3}$ is used as the cut off for the scenario analysis, as suggested by WHO (2013b).

For noise exposure: In Héritier et al. (2017), the adjusted hazard ratio of the CVD mortality per $10 \mathrm{~dB}$ increase of exposure was calculated based on the $\mathrm{L}_{\mathrm{den}}$ from road traffic noise; the analysis considered data from adults ( $>30 \mathrm{y}$ ) included in the Swiss National Cohort. Here, we applied the estimated ratios to the population exposed to $\mathrm{L}_{\mathrm{den}}>55 \mathrm{~dB}$, in particular:

$R R^{\prime}(R R): 1.025(95 \% \mathrm{CI}: 1.018,1.032)$ for population exposed to $\mathrm{L}_{\mathrm{den}}>55 \mathrm{~dB}$

For urban green spaces: based on the meta-analysis by Gascon et al. (2016), there is a reduction of the risk of all-cause mortality per $10 \%$ increase in coverage by green spaces. The ERFs used in the current analysis are as follows:

\section{$R R: 0.99(95 \%: 0.98,1.01)$ reduction in all-cause mortality}

and the threshold value used is the recommended value of $25.6 \%$ estimated for Barcelona by Mueller et al. (2016), which represents the percentage of greenness required for providing universal access to a green space. The reduced relative risk in the municipalities with UGS below the recommended value was estimated by the Eq. (3) (based on the estimations of Mueller et al., 2016):

$\boldsymbol{R}^{\prime}=\boldsymbol{e}^{\frac{\ln (\boldsymbol{R R}) \cdot 2.6 \%-U C S}{10 \%}}$

The attributable fraction $(A F)$ of mortality associated with the above risk factors was calculated from the relative risk $\left(R R^{\prime}\right)$ by the Eq. (4):

$\frac{A F=R R^{\prime}-1}{R R^{\prime}}$

Thus, the attributable number of deaths is the product of $A F$ and the total number of deaths (the baseline mortality).

For the heat-related mortality: the ERFs applied for the Southern and Northern European metropolitan areas were determined through the Baccini et al. (2008) study, where the maximum apparent temperature
$A T$ was calculated by the formula provided in the study $(A T=-2.653$ $+0.994 T_{\max }+0.0153 T_{\text {dew }}^{2}$, where $T_{\max }$ is the daily maximum temperature and $T_{\text {dew }}^{2}$ is the dew point):

- RR: 1.031 (95\% CI: $1.006,1.057)$ per $1{ }^{\circ} \mathrm{C}$ increase in maximum apparent temperature for days with maximum apparent temperature over a threshold of $29.4{ }^{\circ} \mathrm{C}$ (Mediterranean for Lisbon) $/ 32.7{ }^{\circ} \mathrm{C}$ (city-specific for Athens), lag 0-3 (South Europe);

- $R R$ : 1.018 (95\% CI: $1.001,1.036)$ per $1{ }^{\circ} \mathrm{C}$ increase in maximum apparent temperature for days with maximum apparent temperature over a threshold of $23.9{ }^{\circ} \mathrm{C}$ (city-specific for London), lag 0-3 (North Europe).

The relative risk for each day over the threshold mean temperature value was calculated according to the Eq. (5) (Vardoulakis et al., 2014):

$\boldsymbol{R} \boldsymbol{R}^{\prime}=\boldsymbol{e}^{\ln (\boldsymbol{R R}) \cdot \Delta \boldsymbol{T}}$

where $\Delta T$ is the difference between the average of the daily maximum apparent temperature for the current and 3 previous days (lag 0-3) and the threshold value.

The attributable mortality during a year was estimated by summing up the attributable number of deaths over each day of the year.

\section{Results}

Health impact estimates for the environmental public health indicators are presented for the European metropolitan areas.

\subsection{Long-term exposure to air pollution}

The all-cause mortality attributable to $\mathrm{NO}_{2}$ was estimated as number of all-cause deaths per 100,000 inhabitants in the European metropolitan areas (Table 1). The numbers of estimated deaths show the central estimates ranging between 46 and 138 attributable deaths per 100,000 inhabitants for the 1st period and between 37 and 101 for the 2nd period. In the majority of the metropolitan areas, the deaths attributable to $\mathrm{NO}_{2}$ were lower in the 2 nd period compared to the 1 st one; in London the number of deaths estimated in 2005 dropped by $25 \%$ in 2010 and in Athens by $27 \%$. In contrast, in Turin the attributable deaths increased in the 2 nd period by almost $50 \%$, in line with the rise of the $\mathrm{NO}_{2}$ concentrations in the area. The lowest number of attributable deaths was estimated for Stockholm, where air pollution levels were lower than in the other studied metropolitan areas. The spatial

Table 1

All-cause deaths associated with $\mathrm{NO}_{2}$ (minimum/median/maximum across municipalities) per metropolitan area and time period.

\begin{tabular}{lcc}
\hline & $\begin{array}{c}\text { Attributable deaths (per } \\
100,000 \text { inhabitants) }\end{array}$ & $\begin{array}{c}\text { Reduced deaths (per } 100,000 \\
\text { inhabitants) cut-off: } 20 \mu \mathrm{g} / \mathrm{m}^{3}\end{array}$ \\
\hline 1st period & $137.9(124.9,150.6)$ & $89.2(80.7,97.7)$ \\
Athens (2005) & $93.1(84.2,101.9)$ & $43.2(39.0,47.4)$ \\
Barcelona (2005) & $65.8(59.5,72.1)$ & - \\
Lisbon (2004-08) & $95.3(86.3,104.3)$ & $52.0(46.9,57.0)$ \\
London (2005) & $45.6(41.2,50.0)$ & - \\
Stockholm (2005) & $62.2(56.2,68.1)$ & - \\
Turin (2006-08) & $101.1(91.5,110.7)$ & $49.8(45.0,54.6)$ \\
2nd period & $92.7(83.8,101.4)$ & - \\
Athens (2010) & $61.8(55.8,67.7)$ & - \\
Barcelona (2010) & $71.5(64.7,78.3)$ & $34.1(30.8,37.4)$ \\
Lisbon (2009-13) & $36.8(33.2,40.4)$ & - \\
London (2010) & $92.8(83.9,101.6)$ & $42.0(37.9,46.0)$ \\
Stockholm (2010) & Turin (2009-12) & \\
\hline
\end{tabular}

In parentheses, the estimates that are based on the $95 \% \mathrm{CI}$ lower and upper estimates of the RR are reported. 
distribution of the deaths attributable to air pollution estimates across the London municipalities were comparable to the indicator published in the UK Public Health Outcomes Framework (PHOF - https:// fingertips.phe.org.uk/), where the fraction of mortality attributable to $\mathrm{PM}_{2.5}$ was estimated (ranging between $6.3 \%$ and $8.3 \%$ across London in 2010).

Apart from the attributable deaths estimates, the all-cause attributable mortality that may be avoided under the hypothetical scenario that the annual mean $\mathrm{NO}_{2}$ concentrations in each metropolitan area and municipality were reduced down to a cut-off value was also estimated and presented in Table 1 . The value of $20 \mu \mathrm{g} / \mathrm{m}^{3}$ was selected as the cut-off value, as recommended by the HRAPIE experts for impact calculations based on long-term exposure (WHO, 2013b). There were no estimates for Lisbon, Stockholm and for the earliest period for Turin, as in most or all of the municipalities the annual mean concentrations were lower than the suggested cut-off value. Almost half of the deaths attributable to air pollution would be avoided in Athens, Barcelona, London and Turin by the hypothetical reduction in $\mathrm{NO}_{2}$ concentration values (based on 2010 values).

\subsection{Long-term exposure to road traffic noise}

As the indicator used in this study does not comprise data on specific noise levels that the population of the metropolitan areas is exposed to, the given hazard ratio was considered to correspond to the additional risk in mortality due to an increase of the noise levels above the threshold of $55 \mathrm{~dB}$ compared to the risk below that threshold. The number of CVD deaths attributable to road traffic noise exposure in the metropolitan areas for two time periods is reported in Table 2. The values are considerably lower compared to the mortality attributable to $\mathrm{NO}_{2}$; however, it should be noted that not all causes of deaths were accounted for in the current estimates and there was a single $R R$ used for all exposed above $55 \mathrm{~dB}$. The highest number of CVD deaths attributable to road traffic noise exposure was estimated in Athens. In London, the percentage of population exposed to road traffic noise was similar in the two periods; however there was a reduction in CVD deaths attributed to road traffic noise in 2010 compared to the earlier period. In Barcelona and Turin (data only available from the central municipality), the estimates were at the same level for the two periods.

\subsection{Green space coverage}

By using the percentiles of green spaces in the metropolitan areas (Fig. A2) and applying the $R R$ to the municipalities of coverage below the recommended value of $25.6 \%$, the avoided number of attributable all-cause deaths per 100,000 inhabitants was estimated across all municipalities in each metropolitan area (Table 3).

The number of deaths from all causes per 100,000 inhabitants that could be avoided in relation to increased green space coverage was higher in Athens, Barcelona and Lisbon, lower in London and Turin, while in Stockholm there were no estimates of reduced mortality, as

Table 2

CVD deaths attributable to road traffic noise per metropolitan area and time period.

\begin{tabular}{lcc}
\hline \multirow{2}{*}{ Metropolitan area } & \multicolumn{2}{c}{ Attributable CVD deaths (per 100,000 inhabitants) } \\
\cline { 2 - 3 } & 1st period & 2nd period \\
\hline Athens & NA & $15.0(10.9,19.1)(2014)$ \\
$\begin{array}{l}\text { Barcelona } \\
\text { Lisbon }\end{array}$ & $7.2(5.2,9.2)(2007)$ & $6.9(5.0,8.8)(2012)$ \\
$\begin{array}{l}\text { London } \\
\text { Stockholm }\end{array}$ & NA & NA \\
Turin & $10.4(7.5,13.2)(2005)$ & $8.0(5.8,10.2)(2010)$ \\
\hline
\end{tabular}

In Athens, the noise indicator data were monitored in 2014 and here we assume that the values were similar in 2010 , when the most recent mortality data are provided. In parentheses, the estimates that are based on the $95 \% \mathrm{CI}$ lower and upper estimates of RR are reported. NA $=$ not available.
Table 3

Reduced all-cause deaths due to increased access to green spaces per metropolitan area and year.

\begin{tabular}{lcc}
\hline Metropolitan area & \multicolumn{2}{l}{$\begin{array}{l}\text { Reduced all-cause deaths (per 100,000 } \\
\text { inhabitants) }\end{array}$} \\
\cline { 2 - 3 } & 2006 & 2012 \\
\hline Athens & $21.8(0,44.2)$ & $25.8(0,52.5)$ \\
Barcelona & $19.0(0,38.6)$ & $19.0(0,38.6)$ \\
Lisbon & $17.3(0,35.2)$ & $18.1(0,36.6)$ \\
London & $7.8(0,15.9)$ & $6.8(0,13.7)$ \\
Stockholm & 0 & 0 \\
Turin & $10.4(0,21.0)$ & $10.6(0,21.6)$ \\
\hline
\end{tabular}

In parentheses, the estimates that are based on the $95 \% \mathrm{Cl}$ lower and upper estimates of RR are reported.

the green coverage is above the recommended value in all the municipalities. The differences in the estimates depend on the variations of the green spaces in the municipalities of the metropolitan areas, as well as on differences in the baseline mortality ratios of the various populations. It should be noted that in Turin, the all-cause baseline mortality ratios of the population were lower than in other metropolitan areas, so an increase in green spaces was not associated with the expected reduction in the attributable mortality as in the other metropolitan areas with similar percentage coverage of green.

\subsection{Short-term exposure to high temperature}

The attributable deaths per 100,000 inhabitants for the years 2001, 2006 and 2011 due to high temperature (above the temperature threshold value identified in Section 2.2) are shown in Table 4. The deaths per 100,000 inhabitants in Athens ranged between 3.3 in 2006 and 37.1 in 2001 (where there were 147 and 160 days with temperature above threshold, respectively). In Lisbon, the number of attributable deaths was higher in 2006 compared to 2011 due to the particularly high temperatures recorded in 2006, although the number of days with temperature above the threshold was less (136 in 2006 and 160 in 2011). It should be noted that no specific temperature threshold was given for Lisbon by Baccini et al. (2008), therefore the one estimated for the Mediterranean cities was applied for Lisbon. However, as a sensitivity test, if we were to apply the threshold of Valencia $\left(28.2^{\circ} \mathrm{C}\right)$; the number of estimated deaths would be higher by approximately 1.5 times.

The estimated number of deaths was markedly lower for London and particularly low in 2011 compared to the previous years (the number of days when the temperature threshold was exceeded ranged from 25 to 52 per year); our estimates for London were similar to the estimates provided by Hajat et al. (2014) for the 2000s $[4.4(0.9,8.8)$ heat-related deaths per 100,000] although a different ERF was applied in the Hajat et al. (2014) study. In Barcelona, the maximum apparent temperature threshold estimated in the Baccini et al. study $\left(22.4^{\circ} \mathrm{C}\right)$ was exceeded 59-111 days per year, in Stockholm, the maximum apparent temperature threshold of $21.7^{\circ} \mathrm{C}$ was exceeded 38-68 days per year, and in Turin the threshold of $27^{\circ} \mathrm{C}$ was exceeded 68-96 days per year. Therefore, the numbers of deaths attributable to high temperature in Barcelona and Turin would be expected to reach the levels estimated

Table 4

All-cause heat-related deaths per metropolitan area and year.

\begin{tabular}{|c|c|c|c|}
\hline \multirow[t]{2}{*}{ Metropolitan area } & \multicolumn{3}{|c|}{ Attributable all-cause deaths (per 100,000 inhabitants) } \\
\hline & 2001 & 2006 & 2011 \\
\hline Athens & $21.4(4.4,37.1)$ & $16.1(3.3,28.0)$ & $18.7(3.8,32.7)$ \\
\hline Barcelona & NA & NA & NA \\
\hline Lisbon & NA & $13.8(2.9,23.8)$ & $3.8(0.8,6.6)$ \\
\hline London & $6.4(0.4,12.3)$ & $9.0(0.5,17.0)$ & $1.7(0.1,3.3)$ \\
\hline Stockholm & NA & NA & NA \\
\hline Turin & NA & NA & NA \\
\hline
\end{tabular}

$\mathrm{NA}=$ not available 
for the other Southern European metropolitan areas, but attributable deaths could not be calculated for these cities due to the lack of daily mortality data.

\subsection{Road accidents}

The mortality associated with the road safety derived from a direct combination of the two indicators ( $\left.\frac{\text { victims in road accidents } \times \text { fatality ratio due to road traffic accidents }}{\text { fatality ratio due to road traffic accidents }+1}\right) ;$ the results are shown in Table 5. In 2011, the average number of fatalities across municipalities was lower when compared to 2001 in all the municipality areas. In 2011, the number of fatalities was higher for Lisbon and Turin (average values exceeding 5 fatalities per 100,000 inhabitants) and lower in Athens, Barcelona and London, while in Stockholm the values were lower than 0.1 per 100,000 inhabitants.

\subsection{Number of deaths attributable to environmental exposures}

To appreciate the magnitude of the different environmental public health risks across the metropolitan areas, the numbers of deaths (based on population sizes) attributed to environmental exposures long-term exposure to $\mathrm{NO}_{2}$ concentrations (cut-off value is considered), long-term exposure to road traffic noise, urban green spaces, road traffic accidents and short-term exposure to high temperature, were calculated (Fig. 2) for two time periods (earliest - 1st and latest - 2nd periods studied based on data availability) in each metropolitan area.

These results can support the identification of intervention priorities in order to tackle the major environmental public health risks and also offer co-benefits while avoiding unintended consequences for the examined metropolitan areas.

Air pollution, expressed here as $\mathrm{NO}_{2}$ concentrations, is among the most significant environmental risk factors in London, Athens, and Barcelona, as the long-term exposure to $\mathrm{NO}_{2}$ concentrations was associated with the highest numbers of deaths in these urban areas (ranging between 800 and 2300 attributable deaths per year). The reduced number of deaths due to decreases in air pollution in Barcelona was estimated by Mueller et al. (2016) based on assumptions of reduction in $\mathrm{PM}_{2.5}$ concentrations; however direct comparisons with the results of our study were not possible because of the much smaller geographical area covered in the Mueller et al. study.

In Lisbon, London and Turin, road accidents were responsible for a great number of fatalities (average numbers in metropolitan areas ranging between 150 and 300 deaths in 2001); however the number of deaths due to road accidents has decreased over the studied period.

Road traffic noise was associated with CVD deaths comparable to the mortality estimates associated with traffic fatalities, while in Barcelona and London the number of road traffic noise related deaths was higher than the road fatalities. In Mueller et al. (2016), a greater number of attributable deaths associated with road traffic noise under compliance with international exposure recommendations was estimated in Barcelona city (599, 95\% CI: 0, 1009); this could be attributed to the fact that

\section{Table 5}

Number of fatalities in road accidents per metropolitan area and year.

\begin{tabular}{lcc}
\hline Metropolitan area & \multicolumn{2}{l}{$\begin{array}{l}\text { Number of fatalities in road accidents (per } \\
100,000 \text { inhabitants) }\end{array}$} \\
\cline { 2 - 3 } & 2001 & 2011 \\
\hline Athens & $0.5(0,5.3)$ & $0.3(0,3.9)$ \\
Barcelona & $3.9(0,35.6)$ & $1.9(0,25.1)$ \\
Lisbon & $\mathrm{NA}$ & $5.8(0.6,19.2)$ \\
London & $3.7(0.9,14.8)(2002)$ & $1.9(0.3,9.4)$ \\
Stockholm & 0 & 0 \\
Turin & $13.1(0,360.8)$ & $7.5(0,157.7)$ \\
\hline
\end{tabular}

In parentheses, the numbers represent the minimum and maximum ones recorded across the municipalities. $\mathrm{NA}=$ not available. we only calculated CVD mortality here and the $R R$ used in our study was lower; moreover we did not have exposure data at specific noise bands, which may lead to potentially considerable underestimation of the attributable deaths.

In Athens, a greater number of heat-related deaths was estimated compared to the other metropolitan areas; in another study on the heat effects on mortality in European cities (de Donato et al., 2015), the greatest number of attributable deaths were estimated in Athens, where the attributable deaths were twice as high as in London (3200/ 2343 in Athens and 1486/1080 in London cumulatively for 7-year periods).

The positive impact of increased coverage by green spaces was greater in Athens urban area in comparison with the other areas studied.

\section{Conclusions and recommendations}

The environmental public health indicators included in the current analysis - selected based on Delphi and stakeholder iterative processes, as well as data availability - are considered to be important metrics that can be used to assess the environmental conditions based on the areas where most people reside. The HIA methodology applied here enabled quantification of health effects associated with environmental conditions across and within several European metropolitan areas. From the examined environmental public health risks, the greatest mortality impacts were estimated to be associated with long-term exposure to air pollution. The numbers of deaths due to road traffic injuries and those attributed to exposure to road traffic noise were in general of the same order of magnitude, while the health benefits associated with urban green spaces mostly outweigh them.

Based on these, key categories of interventions that could be considered in order to reduce the environmental public health risks and potentially provide co-benefits, such as reduction of social inequalities, in the examined European metropolitan areas include:

Planning interventions, such as the development of green spaces in urban areas and in particular in the metropolitan areas where beneficial health outcomes associated with urban green spaces were identified. A temperature reduction associated with green or 'rural' land surfaces compared with urban land surface types has been discussed in the literature (Heaviside et al., 2016), so interventions to increase green land cover could also be effective at reducing the attributable deaths associated with high temperatures. However, the effectiveness of this intervention would be subject to the specific implementation characteristics (e.g. plant species, canopy design, leaf density).

Traffic management measures that control vehicle flows and the pollutant emissions, such as access restrictions, speed limits may help tackle the number of deaths associated with traffic-related air pollution, road traffic noise and road accidents.

It should be noted, though, that more area- and interventionspecific impact assessment analyses would be required for recommending the design of a particular intervention or set of interventions. The comparisons across the different countries and areas can be valuable in terms of knowledge transfer and in identifying effective policy measures.

A number of limitations associated with the current analysis should be highlighted. These include data availability: 1) the required data were not always available for the same years in the different metropolitan areas and for each environmental public health risk factor; 2) the delimitation of the metropolitan area taken for this study was different across the countries (e.g. for Barcelona, only the municipalities with $>10,000$ inhabitants were considered); 3 ) the national specificities often lead to differences in indicators definitions; and 4) the 

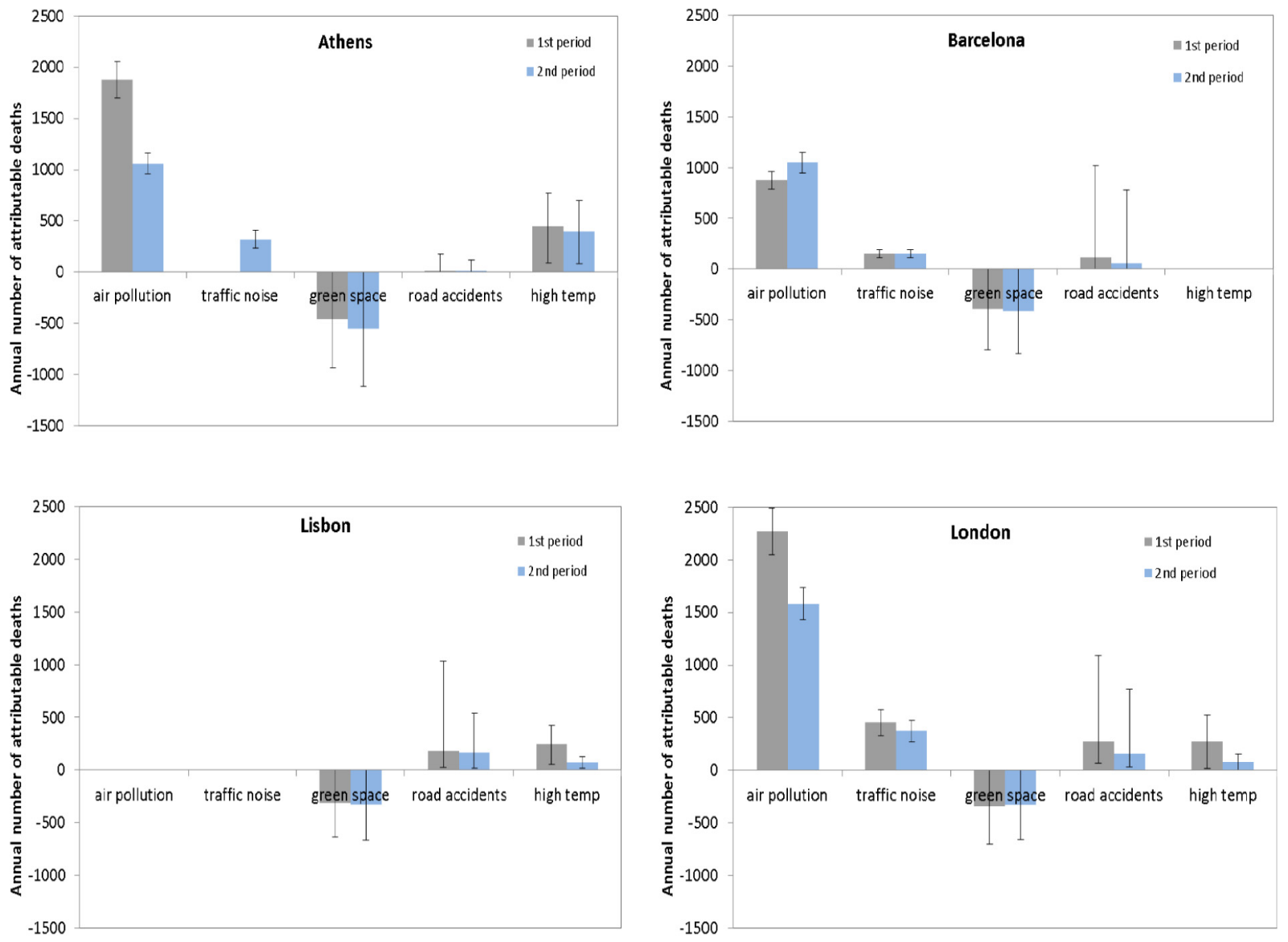

\section{Stockholm}

NO RISKS

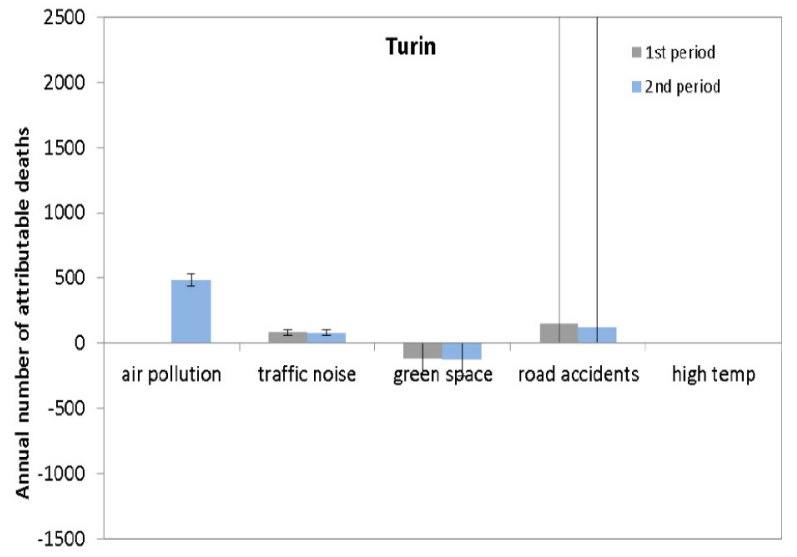

Fig. 2. Number of deaths per year attributable to environmental exposure per metropolitan area and for two time periods.

disaggregation level is different between metropolitan areas (Barcelona, Stockholm and Turin provided data at lower local administrative unit level - LAU2).

Other data related limitation is the use of weather data from one monitoring station for each metropolitan area; the data may not be representative of the whole area population exposure to high temperatures. The use of $\mathrm{NO}_{2}$ concentrations as an indication of air pollution in the metropolitan areas is appropriate for areas where traffic is a major contributor to air pollution, but $\mathrm{NO}_{2}$ may not be the most representative air pollution indicator in areas where other non-traffic sources (e.g. industrial facilities, wood burning, long-range transport) are more dominant. The population exposure to road traffic noise data use a single threshold and this may not accurately reflect the fact that risk increases as noise level increases.
The limitations also include the selection of the applied ERFs that came from multiple sources: one of them (the association between long-term exposure to $\mathrm{NO}_{2}$ concentrations and total mortality) was derived from a meta-analysis based on epidemiological evidence mainly from northern European countries that may not be directly applicable to all the areas studied, while the other ERFs were defined in different epidemiological studies.

Moreover, the environmental public health indicators included were not totally independent from each other, so the specific health risks/ benefits cannot be fully quantified in each metropolitan area, which points to the need for developing ERFs that consider multiple exposures and impacts on health.

Nevertheless, the use of HIA framework in the current analysis enabled us to characterise and quantify the environmental public health 
risks across the six European metropolitan areas. The quantitative estimates of mortality provided here can be used to inform the prioritisation of interventions that aim to improve public health in urban areas. They may also guide studies on environmental inequalities across and within the metropolitan areas. The fine geographical scale of the current calculations (municipal level) allows the identification of specific parts of the metropolitan areas that require improvements in the environmental conditions; this information could be useful at prioritising local interventions in urban areas.

Finally, for future analysis of environmental public health indicators for policy recommendations we would draw the attention to:

Selecting/collecting environmental public health indicators: a comprehensive set of environmental public health indicators is required to be collected and analysed, in order to enable the assessment of a wide range of environmental policies and interventions. Nevertheless, particular attention should be given to the selection of data sources, as the use/processing of comparable in time and space data is crucial;

Combining health effects - development of a composite metric: the development of a composite metric for characterising the environmental public health quality in an integrated way would address the difficulty of distinguishing the health effects associated with the different indicators while analysing a wide range of them.

\section{Acknowledgments}

This research is embedded in the EURO-HEALTHY project which received funding from the European Union's Horizon 2020 - Research and Innovation Framework Programme under grant agreement No 643398. The work of the UK Small Area Health Statistics Unit (SAHSU) is funded by Public Health England as part of the MRC-PHE Centre for Environment and Health, funded also by the UK Medical Research Council (MR/L01341X/1). The authors would like to thank Robel Feleke and Graeme Walsh from Public Health England for providing the mortality data in London, Isabel Trevenna and Lau Magro from the Office for National Statistics UK for the population data in London, Dr. Danielle Vienneau from Swiss TPH for her support at obtaining the pollution maps, as well as other data sources. The authors would also wish to acknowledge Professor George Kallos from the Department of Atmospheric Physics of the National and Kapodistrian University of Athens for his valuable advice on the temperature data, Benjamin Fenech and Georgia Rodgers from Public Health England for advising on noise exposure and health impacts and Emer O'Connell from Public Health England for her input on heat-related health effects.

\section{Appendix A. Supplementary data}

Supplementary data to this article can be found online at https://doi. org/10.1016/j.scitotenv.2018.12.130.

\section{References}

Analitis, A., Katsouyanni, K., Biggeri, A., et al., 2008. Effects of cold weather on mortality: results from 15 European cities within the PHEWE project. Am. J. Epidemiol. 168, 1397-1408.

Atkinson, R.W., Butland, B.K., Dimitroulopoulou, C., Heal, M.R., Stedman, J.R., Carslaw, N., Jarvis, D., Heaviside, C., Vardoulakis, S., Walton, H., Anderson, H.R., 2016. Long term exposure to ambient ozone and mortality: a quantitative systematic review and meta-analysis of evidence from cohort studies. BMJ Open 6, e009493. https://doi. org/10.1136/bmjopen-2015-009493.

Baccini, M., Biggeri, A., Accetta, G., Kosatsky, T., Katsouyanni, K., Analitis, A., Anderson, H.A., Bisanti, L., D'Ippoliti, D., Danoca, J., et al., 2008. Heat effects on mortality in 15 European cities. Epidemiology 19, 711-719.

Basner, M., McGuire, S., 2018. WHO environmental noise guidelines for the European Region: a systematic review on environmental noise and effects on sleep. Int. J. Environ. Res. Public Health 15 (3), 519.
Basu, R., Feng, W.Y., Ostro, B.D., 2008. Characterising temperature and mortality in nine California counties. Epidemiology 19, 138-145.

COMEAP, 2010. Mortality effects of long-term exposure to particulate air pollution in the UK. https://www.gov.uk/government/publications/comeap-mortality-effects-oflong-term-exposure-to-particulate-air-pollution-in-the-uk.

COMEAP, 2015. Quantification of mortality and hospital admissions associated with ground-level ozone. https://www.gov.uk/government/publications/comeap-quantification-of-mortality-and-hospital-admissions-associated-with-ground-level-ozone.

COMEAP, 2016. Long-term exposure to air pollution and chronic bronchitis. https://www. gov.uk/government/publications/comeap-long-term-exposure-to-air-pollution-andchronic-bronchitis.

COMEAP, 2018. Associations of long-term average concentrations of nitrogen dioxide with mortality. https://www.gov.uk/government/publications/nitrogen-dioxide-effects-on-mortality.

Copernicus, 2018. Land monitoring service - urban Atlas. http://land.copernicus.eu/local/ urban-atlas.

Costa, C., Mitsakou, C., Franke, C., Corman, D., Willaert, D., Camprubi, L., Lustigova, M. Coue, N., Tenaiileau, Q., Rodopoulou, S., 2017. Collecting data at municipal level in Europe. The EURO-HEALTHY Approach for Data Collection and Access. International Conference on Urban Health, Coimbra Portugal 26-29 September.

Dadvand, P., Bartoll, X., Basagaña, X., Dalmau-Bueno, A., Martinez, D., Ambros, A., Cirach, M., Triguero-Mas, M., Gascon, M., Borrell, C., Nieuwenhuijsen, M.J., 2016. Green spaces and general health: roles of mental health status, social support, and physical activity. Environ. Int. 91, 161-167.

de Donato, F., Leone, M., Scortichini, M., de Sario, M., Katsouyanni, K., Lanki, T., Basagana, X., Ballester, F., Astrom, C., Paldy, A., Pascal, M., Gasparini, A., Menne, C., Michelozzi, P., 2015. Changes in the effect of heat on mortality in the last 20 years in nine European cities. Results from the PHASE project. Int. J. Environ. Res. Public Health 12 (12) 15567-15583.

de Hoogh, K., Gulliver, J., Donkelaar, A.V., Martin, R.V., Marshall, J.D., Bechle, M.J. Cesaroni, G., Pradas, M.C., Dedele, A., Eeftens, M., Forsberg, B., Galassi, C. Heinrich, J., Hoffmann, B., Jacquemin, B., Katsouyanni, K., Korek, M., Künzli, N., et al., 2016. Development of west-European $\mathrm{PM}_{2.5}$ and $\mathrm{NO}_{2}$ land use regression models incorporating satellite-derived and chemical transport modelling data. Environ. Res. 151, 1-10.

Defra, 2014. Environmental noise: valuing impacts on: sleep disturbance, annoyance, hypertension, productivity and quiet. November 2014. A Report Informed by: The Interdepartmental Group on Costs and Benefits Noise Subject Group.

Dimitroulopoulou, S., Mitsakou, C., 2018. Review of Health Impact Assessment Tools for Active Travel/local Travel Plans (PHE report).

EU - European Union, 2014. Taking stock of the Europe 2020 strategy for smart, sustainable and inclusive growth. https://eur-lex.europa.eu/resource.html?uri=cellar: 21493022-a617-11e3-8438-01aa75ed71a1.0003.05/DOC 18format=PDF.

EUROSTAT, 2016. Urban Europe - statistics on cities, towns and suburbs. http://ec.europa.eu/eurostat/statistics-explained/index.php?title=Urban_Europe_\%E2\%80\%94 statistics_on_cities,_towns_and_suburbs.

Freitas, Â., Santana, P., Oliveira, M.D., Almendra, R., Bana Costa, J.C., Bana Costa, C.A., 2018 Indicators for evaluating European population health: a Delphi selection process. BMC Public Health 18. https://doi.org/10.1186/s12889-018-5463-0.

Gascon, M., Triguero-Mas, M., Martinez, D., Dadvand, P., Rojas-Rueda, D., Plasencia, A., Nieuwenhuijsen, M., 2016. Residential green spaces and mortality: a systematic review. Environ. Int. 86, 60-67.

Gasparrini, A., Guo, Y., Hashizume, M., et al., 2015. Mortality risk attributable to high and low ambient temperature: a multicountry observational study. Lancet 386 (9991) 369-375.

Gowers, A.M., Miller, B.G., Stefman, J.R., 2014. Estimating local mortality burdens associated with particulate air pollution. Public Health England (PHE) Report.

Gronlund, C.J., Zanobetti, A., Schwartz, J.D., Wellenius, G.A., O'Neill, M.S., 2014. Heat, heat waves and hospital admissions among the elderly in the United States, 1992-2006. Environ. Health Perspect. 122, 1187-1192.

Gulia, S., Nagendra, S.M.S., Khare, M., Khanna, I., 2015. Urban air quality management - a review. Atmos. Pollut. Res. 6 (2), 286-304.

Guski, R., Schreckenberg, D., Schuemer, R., 2017. WHO environmental noise guidelines for the European Region: a systematic review on environmental noise and annoyance Int. J. Environ. Res. Public Health 2017 (14), 1539. https://doi.org/10.3390/ ijerph14121539.

Hajat, S., Vardoulakis, S., Heaviside, C., Eggen, B., 2014. Climate change effects on human health: projections of temperature-related mortality for the UK during the 2020s, 2050s and 2080s. J. Epidemiol. Community Health https://doi.org/10.1136/jech2013-202449.

Halonen, J.I., Hansell, A.L., Gulliver, J., et al., 2015. Road traffic noise is associated with increased cardiovascular morbidity and mortality and all-cause mortality in London. Eur. Heart J. 36 (39), 2653-2661.

Heaviside, C., Vardoulakis, S., Cai, X.-M., 2016. Attribution of mortality to the Urban Heat Island during heatwaves in the West Midlands, UK. Environ. Health 15 (Suppl. 1), 27.

Heaviside, C., Macintyre, H., Vardoulakis, S., 2017. The urban heat island: implications for health in a changing environment. Published online. Current Environmental Health Reports https://doi.org/10.1007/s40572-017-0150-3 (Jul 10).

Héritier, H., Vienneau, D., Foraster, M., Eze, I.C., Schaffner, E., Thiesse, L., Rudzik, F. Habermacher, M., Köpfli, M., Pieren, R., Brink, M., Cajochen, C., Wunderli, J.M. Probst-Hensch, N., Röösli, M., 2017. Transportation noise exposure and cardiovascular mortality: a nationwide cohort study from Switzerland. Eur. J. Epidemiol. 32 (4) 307-315.

Hoek, G., Krishnan, R.M., Beelen, R., Peters, A., Ostro, B., Brunekreef, B., Kaufman, J., 2013 Long-term air pollution exposure and cardio-respiratory mortality: a review. Environ. Health 12,43 . 
James, P., Banay, R.F., Hart, J.E., Laden, F., 2015. A review of the health benefits of greenness. Curr. Epidemiol. Rep. 2, 131-142.

Kluizenaar, Y., Passchier-Vermeer, W., Miedema, H.M.E., 2001. Adverse effects of noise exposure on health: a state of the art summary. TNO Rep. 2001, 171

Miedema, H.M.E., Vos, H., 2007. Associations between self-reported sleep disturbance and environmental noise based on reanalyses of pooled data from 24 studies. Behav. Sleep Med. 5, 1-20.

Mueller, N., Rojas-Rueda, D., Basagaña, X., Cirach, M. ColeHunter, T, Dadvand, P. DonaireGonzalez, D., Foraster, M., Gascon, M., Martinez, D., Tonne, C., Triguero-Mas, M., Valentín, A., Nieuwenhuijsen, M., 2016. Urban and transport planning related exposures and mortality: a health impact assessment for cities. Environ. Health Perspect. https://doi.org/10.1289/EHP220.

Munzel, T., Gori, T., Babisch, Q., Basner, M., 2014. Cardiovascular effects of environmental noise exposure. Eur. Heart J. 35 (13), 829-836.

Perez, L., Trueb, S., Cowie, H., Keuken, M.P., Mudu, P., Ragettli, M.S., Sarigiannis, D.A. Tobolik, M., Tuomisto, J., Vienneau, D., Sabel, C., Kunzli, N., 2015. Transport-related measures to mitigate climate change in Basel, Switzerland: a health-effectiveness comparison study. Environ. Int. 85, 111-119.

Pinto, et al., 2017. Spatial planning for health: an evidence resource for planning and designing healthier places. PHE report. https://www.gov.uk/government/publications/ spatial-planning-for-health-evidence-review.

Robine, J.-M., Cheung, S.L.K., Le Roy, S., Van Oyen, H., Griffiths, C., Michel, J.-P., Herrmann, F.R., 2008. Death toll exceeded 70,000 in Europe during the summer of 2003. C. R. Biol. 331, 171-178.

Samoli, E., Atkinson, R.W., Analitis, A., Fuller, G.F., Gree, D.C., Mudway, I., Anderson, H.R Kelly, F.J., 2016. Associations of short-term exposure to traffic-related air pollution with cardiovascular and respiratory hospital admissions in London, UK. Occup. Environ. Med. https://doi.org/10.1136/oemed-2015-103136.

Santana, P., Costa, C., Freitas, A., et al., 2017. Atlas of Population Health in European Union Regions. Imprensa da Universidade de Coimbra 978-989-26-1462-5.

Shen, Y., Hermans, E., Bao, Q., Brijs, T., Wets, G., 2013. Road safety development in Europe: a decade of changes (2001-2010). Accid. Anal. Prev. 60, 85-94.

Tamosiunas, A., Grazuleviciene, R., Luksiene, D., Dedele, A., Reklaitiene, R., Baceviciene, M. Vencloviene, J., Bernotiene, G., Radisauskas, R., Malinaiskiene, V., Milinaviciene, E. Bobak, M., Peasey, A., Nieuwenhuijsen, M.J., 2014. Accessibility and use of urban green spaces and cardiovascular health: findings from a Kaunas cohort study. Environ. Health 13, 20

van den Bosch, M., Mudu, P., Uscila, V., Barrdahl, M., Kulinkina, A., Staatsen, B., Swart, W. Kruize, H., Zurlyte, I., Egorov, A.I., 2016. Development of an urban green space indicator and the public health rationale. Scand. J. Public Health 44, 159-167.

van Kempen, E., Casas, M., Pershagen, G., Foraster, M., 2018. WHO environmental noise guidelines for the European region: a systematic review on environmental noise and cardiovascular and metabolic effects: a summary. Int. J. Environ. Res. Public Health 15, 379. https://doi.org/10.3390/ijerph15020379.

Vardoulakis, S., Dear, K., Hajat, S., Heaviside, C., Eggen, B., McMichael, A.J., 2014. Comparative assessment of the effects of climate change on heat and cold related mortality in the UK and Australia. Environ. Health Perspect. 122, 1285-1292.

Vardoulakis, S., Dimitroulopoulou, S., Mitsakou, C., Heaviside, C., Katsouyanni, K., Samoli, E., Santana, S., 2016. Developing environmental public health indicators for European Metropolitan Areas. International Conference on Urban Risks 2016, Lisbon Portugal, 30 June-2 July 2016.

Vardoulakis, S., Kettle, R., Cosford, P., Lincoln, P., Holgate, S., Grigg, J., Kelly, F., Pencheon, D., 2018. Local action on outdoor air pollution to improve health. Int. J. Public Health 63, 557-565

Vienneau, D., de Hoogh, K., Bechle, M.J., Beelen, R., van Donkelaar, A., Martin, R.V., Millet, D.B., Hoek, G., Marshall, J.D., 2013. Western European land use regression incorporating satellite- and ground-based measurements of $\mathrm{NO}_{2}$ and $\mathrm{PM}_{10}$. Environ. Sci. Technol. 47, 13555-13564.

Wang, H., Naghavi, M., Allen, C., et al., 2016. Global, regional, and national life expectancy, all-cause mortality, and cause-specific mortality for 249 causes of death, 1980-g: a systematic analysis for the Global Burden of Disease Study 2015. Lancet 388, 1459-1544

Woodcock, J., Tainio, M., Cheshire, J., O'Brien, O., Goodman, A., 2014. Health effects of the London bicycle sharing system health impact modelling study. BMJ https://doi.org/ 10.1136/bmj.g425.

World Health Organisation - WHO, 2013a. European Facts and Global Status Report on Road Safety. WHO Regional Office for Europe, Copenhagen.

World Health Organisation - WHO, 2013b. Health Risks of Air Pollution in Europe HRAPIE Project: Recommendations for Concentration-response Functions for Costbenefit Analysis of Particulate Matter, Ozone and Nitrogen Dioxide.

World Health Organisation - WHO, 2016. Urban Green Spaces and Health. WHO Regional Office for Europe, Copenhagen.

World Health Organisation - WHO, 2017. Urban Green Space Interventions and Health: A Review of Impacts and Effectiveness. WHO Regional Office for Europe, Copenhagen http://www.euro.who.int/__data/assets/pdf_file/0010/337690/FULL-REPORT-forLLP.pdf?ua= 1 .

World Health Organisation - WHO, 2018a. Environmental noise guidelines for the European Region. http://www.euro.who.int/en/health-topics/environment-andhealth/noise/environmental-noise-guidelines-for-the-european-region.

World Health Organisation - WHO, 2018b. Definition of health impact assessment (HIA). http://www.euro.who.int/en/health-topics/environment-and-health/health-impactassessment/definition-of-health-impact-assessment-hia. 